\title{
Results of chemotherapy in 30 AIDS patients with symptomatic pulmonary Kaposi's sarcoma
}

Jacques L Cadranel, Sammy Kammoun, Sylvie Chevret, Antoine Parrot, Michel Denis, Cécile Winter, Marie-France Carette, Willy Rozenbaum, Georges M Akoun, Charles M Mayaud

\begin{abstract}
Background - The aim of this study was to report the effects of a three-drug chemotherapy regimen in patients with symptomatic AIDS-related pulmonary Kaposi's sarcoma and to analyse prognostic factors for survival.

Methods - Thirty consecutive HIV seropositive patients with respiratory symptoms and proven pulmonary Kaposi's sarcoma were treated with the same therapeutic regimen comprising adriamycin $\left(30 \mathrm{mg} / \mathrm{m}^{2}\right)$, bleomycin $\left(10 \mathrm{mg} / \mathrm{m}^{2}\right)$, and vincristine ( $2 \mathrm{mg}$ ) administered intravenously once every four weeks.

Results - Two patients died during the first course of chemotherapy. In the other 28 cases dyspnoea improved and $\mathrm{Pao}_{2}$ rose despite minimal $(n=17)$ or no $(n=11)$ improvement in the chest radiographic appearance. The median survival from the beginning of chemotherapy was 6.5 months. Poor prognostic factors for survival were: (1) absence of cutaneous $\mathrm{Ka}$ posi's sarcoma; (2) previous opportunistic

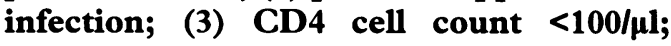
(4) leucocytes <3500/ $\mu$; (5) haemoglobin $<10 \mathrm{~g} / \mathrm{dl}$; and (6) absence of radiological response. Of the 28 patients 24 experienced at least one episode of neutropenia which was associated with bacterial infection in 16 cases.

Conclusions - Chemotherapy may improve respiratory impairment in patients with extensive pulmonary Kaposi's sarcoma but the outcome remains poor. The efficacy of chemotherapy may be limited by neutropenia.
\end{abstract}

(Thorax 1994;49:958-960)

Radiologie, Hôpital

Tenon

M F Carette

Service de Maladies Infectieuses, Hôpital Rothschild

W Rozenbaum

Paris, France

Reprint requests to: Dr JL Cadranel, Service de Pneumologie et Réanimation Respiratoire, Hôpital Tenon 4 rue de la Chine, 75020 Paris, France.

Received 5 August 1993 Returned to authors 8 October 1993

Revised version received 18 May 1994

Accepted for publication

17 June 1994

Cutaneous Kaposi's sarcoma occurs in 10-20\% of HIV infected patients. ${ }^{1}$ The prognosis of Kaposi's sarcoma is related in part to visceral involvement, especially the lung. ${ }^{12}$ The frequency of pleuropulmonary disease in Kaposi's sarcoma represents less than $15 \%$ of pneumonitis observed in HIV infected patients. ${ }^{1}$ It has been identified in $20-40 \%$ of patients with respiratory symptoms and cutaneous Kaposi's sarcoma, and found at necropsy in $40-75 \%$ of these patients. ${ }^{1}$ Without treatment the prognosis of symptomatic pulmonary Kaposi's sarcoma is poor, with a mean survival time after diagnosis of less than three months. ${ }^{1}$ However, some investigators have shown that this can be improved with cytotoxic chemotherapy. ${ }^{3}$ The efficacy of this approach has been evaluated in several small series ${ }^{4-8}$ in which some prognostic factors for survival have been identified. ${ }^{45} \mathrm{We}$ report our results in 30 consecutive HIV seropositive patients with symptomatic pulmonary Kaposi's sarcoma treated with a three-drug chemotherapy regimen between July 1988 and August 1990, and analyse the prognostic factors for survival.

\section{Methods \\ PATIENTS}

During the study period all patients admitted to our chest department for respiratory symptoms related to proven pulmonary Kaposi's sarcoma and without associated active pulmonary infection were treated with the same therapeutic regimen, after giving informed consent. Twenty nine patients were homosexual and one was infected by a blood transfusion. Twenty one had full blown AIDS having had opportunistic infections $(n=20)$, or previously diagnosed cutaneous Kaposi's sarcoma $(n=23)$, or both. In seven patients no skin lesions were present at the time of diagnosis of pulmonary Kaposi's sarcoma. Cutaneous Kaposi's sarcoma had been previously treated, without significant clinical response, with interferon in 12 patients, bleomycin in two, and vinca alkaloid in two. The mean (SD) duration of respiratory signs and symptoms before diagnosis of pulmonary Kaposi's sarcoma was 2.8 (2) months (range 1-7). All patients had $\mathrm{PaO}_{2}$ below $10.5 \mathrm{kPa}$ (mean (SD) $8.0(1.4) \mathrm{kPa})$. Chest radiographs showed opacities in both lungs in all patients. The pretreatment laboratory findings are shown in table 1 .
DIAGNOSIS OF PULMONARY KAPOSI'S SARCOMA In 26 patients the diagnosis of pulmonary Kaposi's sarcoma was established by fibreoptic bronchoscopy. When the bronchi were normal a thoracotomy $(n=3)$ or thoracoscopy $(n=$ 1) was performed to reveal macroscopically evident Kaposi's sarcoma lesions which were confirmed histologically. In each patient evidence of pulmonary infection was sought by bronchoalveolar lavage. We also looked for an extrapulmonary infection. Patients were classified according to the TIS criteria (Tumour, Immune system, Systemic illness) of Krown et $a l^{2}$ : nine patients $(30 \%)$ were classified as stage $\mathrm{T} 1-\mathrm{I} 0-\mathrm{S} 1$ and the remaining $21(70 \%)$ as stage T1-I1-S1. 
Table 1 Characteristics of patients $(n=30)$ and pretreatment laboratory findings

\begin{tabular}{lc}
\hline $\begin{array}{l}\text { Prior cutaneous Kaposi's } \\
\text { sarcoma }\end{array}$ & $23(78 \%)$ \\
$\begin{array}{l}\text { Mean (range) haematological } \\
\text { values (per } \mu \mathrm{l})\end{array}$ & \\
CD4 lymphocytes & $170(10-600)$ \\
Leucocytes & $3850(1100-11900)$ \\
Platelets & $174000(50000-344000)$ \\
Haemoglobin & $10 \cdot 4(7 \cdot 9-12 \cdot 8)$ \\
& $30(100 \%)$ \\
Pulmonary symptoms & $30(100 \%)$ \\
Dyspnoea & $24(80 \%)$ \\
Cough & $14(47 \%)^{*}$ \\
Chest pain & $9(30 \%)$ \\
Haemoptysis & $4(13 \%)$ \\
Fever $\geqslant 38 \cdot 5^{\circ} \mathrm{C}$ & $30(100 \%)$ \\
Chest radiograph & $27(90 \%)$ \\
Diffuse interstitial pattern & $11(37 \%)$ \\
Pulmonary nodules & $24(80 \%)$ \\
Pleural effusion & \\
\hline
\end{tabular}

* Without associated infection

\section{TREATMENT REGIMEN}

The treatment regimen comprised adriamycin $\left(30 \mathrm{mg} / \mathrm{m}^{2}\right)$, bleomycin $\left(10 \mathrm{mg} / \mathrm{m}^{2}\right)$, and vincristine $(2 \mathrm{mg})$ administered intravenously once every four weeks from the date of diagnosis to the time of death or deterioration. Chemotherapy was postponed for a week when the neutrophil or platelet count dropped below $1000 / \mu \mathrm{l}$ and $50000 / \mu \mathrm{l}$ respectively, or if a fever $>38.5^{\circ} \mathrm{C}$ or a new uncontrolled infection occurred. Nine patients were given methylprednisolone $(120 \mathrm{mg}$ on day 1 or from day 1 to day 3 ) in addition during the first course of chemotherapy because of acute respiratory failure. All patients were given co-trimoxazole or dapsone as prophylaxis for Pneumocystis carinii infection. To avoid possible zidovudine toxicity the drug was either stopped or tapered to $300 \mathrm{mg} /$ day for 10 days of the month only.

END POINTS AND RESPONSE CRITERIA

Subjective improvement in respiratory symptoms and objective increase of $\mathrm{PaO}_{2}$ were assessed after the first course of chemotherapy. Radiological pulmonary response was assessed by blind examination of the chest radiograph by three observers four weeks after the first, second, and third courses - that is, when the next course was due. Because of the radiological features of pulmonary Kaposi's sarcoma observed in our patients (peribronchovascular thickening without measurable nodules) this response was not defined precisely as recommended by Krown et al. ${ }^{2}$ Thus, a radiological response was considered as being present only when identified by all three investigators. Overall survival from the date of chemotherapy defined the second end point.

Table 2 Factors associated with shorter survival time

\begin{tabular}{|c|c|c|}
\hline Factors & $\begin{array}{l}\text { Survival } \\
\text { time } \\
\text { (months) }\end{array}$ & $p$ \\
\hline $\begin{array}{l}\text { Absence of cutaneous Kaposi's sarcoma } \\
\text { Prior opportunistic infection } \\
\mathrm{CD} 4<100 / \mu \mathrm{l} \\
\text { Haemoglobin }<10 \mathrm{~g} / \mathrm{dl} \\
\text { Leucocytes }<3500 / \mu \mathrm{l} \\
\text { Absence of chest radiographic response }\end{array}$ & 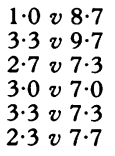 & $\begin{aligned} & 0.0001 \\
&<<.01 \\
&<<.01 \\
&<0.01 \\
&<0.02 \\
&<0.02\end{aligned}$ \\
\hline
\end{tabular}

STATISTICAL ANALYSIS

Survival time was analysed by the KaplanMeier method. The prognostic value of several baseline characteristics was selected at the $5 \%$ level by the log rank test; ${ }^{9}$ their joint effects were assessed by the semiparametric Cox's model. ${ }^{9}$

\section{Results}

RESPONSE TO TREATMENT AND SURVIVAL

Two patients died from pulmonary Kaposi's sarcoma following the first course of chemotherapy. In the other 28 patients dyspnoea and cough improved after the first course. This subjective benefit was associated with an improvement in arterial blood gas tensions breathing air $(10.6(2.0) \mathrm{kPa} v 8.0(1.4) \mathrm{kPa}$; $\mathrm{p}<0.0005)$ compared with pretreatment values. These beneficial effects lasted for a mean of 3.5 weeks, but never exceeded eight weeks. A radiological response was observed in 18 of the 28 patients $(64 \%)$. This response was always obtained after the first $(n=12)$ or the second $(n=6)$ course of chemotherapy, was never complete, and was similar in duration to the clinical response. The cutaneous response usually paralleled the pulmonary one.

No patient survived beyond 23 months. The median survival time was 6.5 months (range 1-23) after the first course of chemotherapy, nine months (range 1-23) after the date of diagnosis of pulmonary Kaposi's sarcoma, and 11.4 months (range 2-27) after the onset of respiratory symptoms. The cause(s) of death was identified in 25 patients $(83 \%)$; it was related to Kaposi's sarcoma associated respiratory infection in 10 patients and to respiratory failure due to Kaposi's sarcoma in 12. Three patients died of an extrapulmonary opportunistic infection related to AIDS (see below).

\section{PROGNOSTIC FACTORS}

Previous treatment of cutaneous Kaposi's sarcoma by interferon and/or single drug chemotherapy, pleural effusion on the chest radiograph, degree of hypoxaemia, platelet count before chemotherapy, and the use of adjuvant steroids during the first course of chemotherapy were not statistically related to survival. Unexpectedly, the extent of improvement in $\mathrm{PaO}_{2}$ after the first course of chemotherapy was also of no prognostic value. When considered separately, six factors allowed prediction of a shorter survival as shown in table 2 . Only two independent prognostic factors were still predictive of poor survival after multivariate analysis, however, namely the absence of cutaneous Kaposi's sarcoma and a haemoglobin value $<10 \mathrm{~g} / \mathrm{dl}$ before chemotherapy. The relative risk of death was estimated as being 14-fold and 3.5-fold greater, respectively, in those patients compared with the rest.

COMPLICATIONS

Fever related to bleomycin administration was observed in three patients which was sub- 
sequently prevented by paracetamol. Two cases of peripheral neuropathy and one of clinically asymptomatic cardiomyopathy were observed, related in part to treatment with vincristine and adriamycin. None of the side effects had any influence on the administration of the chemotherapy. By contrast, haematological toxicity (neutropenia: grade $2-3(n=19)$, grade $4(n=$ $5)$, and thrombopenia: grade $2(n=9))$ lengthened the chemotherapy intercycle period from four weeks to 5.6 weeks (range 4-9).

Fever $\left(>38.5^{\circ} \mathrm{C}\right.$ for more than 48 hours) was observed in 16 of the 28 patients. An associated opportunistic infection occurred in five patients at the time of diagnosis of pulmonary Kaposi's sarcoma: cytomegalovirus retinitis $(n=3)$, Pneumocystis carinii pneumonia $(\mathrm{n}=1)$, cerebral toxoplasmosis $(n=1)$. Opportunistic infections occurred during follow up in 10 of the 28 patients.

\section{Discussion}

The overall survival of patients with visceral involvement by Kaposi's sarcoma has only been reported in a few small series, ${ }^{3-81011}$ often not in a homogeneous group of patients with pulmonary Kaposi's sarcoma, ${ }^{511}$ and with different chemotherapeutic regimens. ${ }^{11}$ The results emerging from our study show (1) the discrepancy between a good symptomatic improvement and the insensitivity of radiological response; (2) the modest median survival time of 6.5 months which depended not only on the usual poor prognosis factors for AIDS but also on the absence of associated cutaneous Kaposi's sarcoma at presentation; (3) the high frequency of bacterial infection associated with neutropenia; and (4) the estimated mortality rate of $50 \%$ directly related to progression of pulmonary Kaposi's sarcoma.

Although our patients were similar to those in previous series they had more respiratory symptoms and lower mean $\mathrm{PaO}_{2}$ values. Radiological involvement was worse in $80 \%$ of our patients with pleural effusions, compared with $25-55 \%$ of patients in other series. ${ }^{1}$ Cutaneous Kaposi's sarcoma was absent in nearly $25 \%$ of our patients. The chemotherapy we used was similar to that in all series previously published. ${ }^{3-81011}$

A radiological response was achieved in $64 \%$ of patients which was close to that previously reported (48-93\%). ${ }^{4-611}$ However, unlike other investigators we did not see a complete response but observed dramatic improvements in respiratory symptoms and a rise in $\mathrm{PaO}_{2}$ after the first course. The median survival time remained short, however, similar to that reported in other series. ${ }^{45}$

Several poor prognostic factors previously described in patients with pulmonary Kaposi's sarcoma were also observed in our series (table 2). ${ }^{45}$ Although not previously reported as such, the absence of cutaneous Kaposi's sarcoma was a poor prognostic factor. None of these patients had received chemotherapy before the diagnosis of their pulmonary Kaposi's sarcoma which may explain the absence of cutaneous lesions and/or the poorer prognosis.

The frequency of neutropenia and bacterial infections in our patients considerably lengthened the intervals between chemotherapy courses. It should be emphasised, however, that most of our patients died from bacterial infections or respiratory failure due to progression of the pulmonary Kaposi's sarcoma.

1 White D, Matthay RA. Noninfectious pulmonary complications of infection with human immunodeficiency virus. Am Rev Respir Dis 1989;140:1763-87.

2 Krown SE, Metroka C, Wernz JC. Kaposi's sarcoma in immune deficiency syndrome: a proposal for uniform evaluation, response, and staging criteria. $\mathcal{f}$ Clin Oncol 1989;7:1201-7.

3 Ognibene FP, Steis RG, Macher AM, Liotta L, Gelmann $\mathrm{E}$, Pass HL, et al. Kaposi's sarcoma causing pulmonary infiltrates and respiratory failure in the acquired immunodeficiency syndrome. Ann Intern Med 1985;102: immun

4 Gill PS, Rarick M, McCutchan JA, Slater L, Parker B, Muchmore E, et al. Systemic treatment of AIDS-related Kaposi's sarcoma: results of a randomized trial. $A m \mathcal{F} \mathrm{Med}$ 1991;90:427-33.

5 Gill PS, Akil B, Colletti P, Rarick M, McCutchan JA, Loureiro C, et al. Pulmonary Kaposi's sarcoma: clinical

Laubenstein LJ, Kriger RL, Odajnyk CM, Hymes KB, Laubenstein LJ, Kriger RL, Odajnyk CM, Hymes KB,
Friedman-Kien A, Wernz JC, et al. Treatment of epidemic Kaposi's sarcoma with etoposide or a combination of doxorubicin, bleomycin, and vinblastin. $\mathcal{F}$ Clin Oncol 1984 2:1115-20.

7 Gelmann EP, Longo D, Lane HC, Fauci AS, Masur H, Wesley $M$, et al. Combination chemotherapy of disseminated Kaposi's sarcoma in patients with the acquired immune deficiency syndrome. Am 7 Med 1987;82:456-62.

8 Gill PS, Rarick M, Espina B, Akil B, Loureiro C, BernsteinSinger $\mathrm{M}$, et al. Advanced acquired immune deficiency syndrome-related Kaposi's sarcoma. Results of pilot studsyndrome-related Kaposi's sarcoma. Results of pilot studies using

9 Kalbfleisch JD, Prentic RL. The statistical analysis of failur time data. New York: John Wiley, 1980.

10 Gill PS, Berstein-Singer M, Espina BM, Rarick M, Magy F, Montgomery T, et al. Adriamycin, bleomycin and vincristin chemotherapy with recombinant granulocyte-macrophage colony-stimulating factor in the treatment of rophage colony-stimulating factor in the treatment of

11 Sloand E, Kumar PN, Pierce PF. Chemotherapy for patients with pulmonary Kaposi's sarcoma: benefit of filgrastim in supporting dose administration. South Med F 1993;86: 1219-24. 